\title{
Medical Education in Pakistan: Challenges \& Way Forward
}

\author{
Khan, J.S., ${ }^{1}$ Strivens, J. ${ }^{2}$
}

\begin{abstract}
There have been many conceptual and practical drawbacks in how the medical education has been developed in Pakistan. Though there has been expansion in the medical education sector since the creation of this country, the doctors available for the existing population are not sufficient thus affecting the overall quality of medical care. To understand this particular issue, associated factors are required to be analyzed. Medical education in Pakistan is affected by the growth of the private medical colleges, mal-distribution of resources, traditional curricula that focus on theoretical knowledge more than the practical training and absence of uniform admission processes in the public and the private sectors. To keep pace with socio-economic development and the quality of medical education, there is a need for re-evaluation of every facet at each and every level: creation of strong and efficient accreditation system; promotion of equality in the distribution of resources; curriculum redesigning with stricter implementation of guidelines provided by Pakistan Medical Commission (PMC) and improvement in the teaching and assessment methodologies for graduates in the medical profession; thus providing optimum healthcare delivery ensuring competence concomitantly and bringing positive change in the system.
\end{abstract}

Keywords: Medical Education, Medical Care, Medical Colleges, Pakistan

\section{Introduction}

Since independence, Pakistan has produced many competent and well-qualified health professionals, despite challenges. However, the roots of the present system of medical education are in the colonial era and there has been slow progress in the development of this sector in Pakistan. Sheikh, Naqvi, Sheikh, Naqvi, \& Bandukda (2012) identified many issues and shortcomings regarding medical education in Pakistan. He associated a number of challenges

${ }^{1} \mathrm{CMH}$ Lahore Medical College \& Institute of Dentistry, National University of Medical Sciences, Pakistan

2University of Liverpool, United Kingdom

Corresponding author: Prof Dr Junaid Sarfraz Khan junaidsarfraz@hotmail.com attitude on the part of policymakers, which in in this regard with a lack of a proper facilitating his view needed to be addressed for any progress in this sector to materialize.

Anjum (2018) notes that despite growth in the number of medical colleges the desired impact on healthcare indices has not been achieved, which has also raised a question regarding the quality of medical education in Pakistan. $\mathrm{He}$ points to multiple weaknesses in the provision of education, including inequality in the distribution of resources, a poor assessment system, outdated curricula, neglected research and untrained faculty. Although there have been discussions, changes in policy, recommendations and interventions the general picture is still bleak. Table 1 . summarises the major issues at present. 
Table 1: Summary of issues highlighted by Sheikh et al. (2012) and Anjum (2018)

- Despite having approximately 169 medical colleges in Pakistan, the ratio of doctors per head of population is quite low, roughly 1:1500.

- Problems exist in the distribution, equity and access to healthcare facilities despite the increases in medical colleges.

- The medical curriculum does not cater to the health needs of the population due to lack of periodical revision.

- Medical education is directed towards passing exams due to the lack of emphasis on clinical training and failure to integrate basic and clinical sciences.

- Due to the growth of private medical colleges compared to the government sector - 108 medical or dental colleges compared to 61 - the standard of medical education has been diluted.

- Innovative curricula, faculty development programmes and better assessment methods are required for quality health care education.

There is very little literature available and that exists continues to identify the same set of issues and challenges that seem not to have been addressed over decades. The excessive population growth is a major issue and its rate has risen steadily from $2.6 \%$ per annum in the early 1960 s to a high of about $3.5 \%$ in the late 1980 s and the population is currently estimated at 210.13 million. It is estimated that the population will continue to rise sharply over to 324 million by 2050 . All the efforts to meet the demands of this expanding population have been unable to keep pace. Pakistan population is increasing day by day and according to the 2017 Census the total population of Pakistan was 207 million compared to the 65 million in 1972 Census.

Organization of the healthcare sector in Pakistan

The growth of the healthcare workforce and medical colleges has been a priority in Pakistan over the past 68 years.
The healthcare delivery system is divided into primary healthcare units (Rural health centres and basic health units), secondary (tehsil headquarter and district headquarter) hospitals and tertiary hospitals (teaching hospitals which are mostly located in major cities). Table 2. According to the Pakistan Economic Survey 2019-20, there are 5,472 basic health units, 670 rural health centres, 5,743 dispensaries and 1,282 public hospitals. However, Habib \& Khan (2017) stated that there was an acute shortage of in-patient beds; the delivery of babies was being carried out on floors and emergency treatment was being provided with up to three patients on a single bed. The military, the railways and airlines also provide healthcare services to their employees and families. Table 2 represents total number of doctors, dentists, nurses, mid-wives and LHVs. The density of physicians, nurses and midwives is below the world averages according to a report by the WHO 2016 suggesting an excessive workload with unfavourable effects on the quality of healthcare leading to poor patient outcome.

Table 2: National Medical and Health Establishments, Progressive Number

\begin{tabular}{|c|c|c|c|c|c|c|c|c|}
\hline 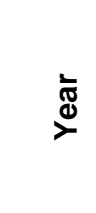 & $\begin{array}{l}\frac{0}{\pi} \\
\frac{\pi}{0} \\
\frac{0}{0} \\
\frac{0}{1}\end{array}$ & 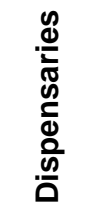 & 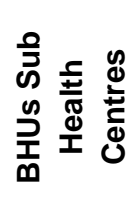 & 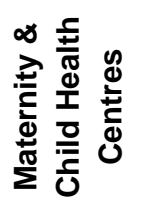 & 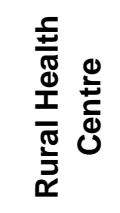 & 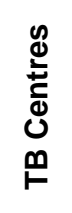 & $\begin{array}{l}\frac{0}{0} \\
\stackrel{0}{0} \\
\frac{0}{\pi} \\
\frac{\pi}{0} \\
\qquad\end{array}$ & 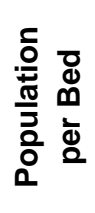 \\
\hline 1951 & 306 & 823 & - & 110 & - & 3 & 14,741 & 2,454 \\
\hline 1972 & 496 & 2,137 & 249 & 675 & 87 & 82 & 35,337 & 1,792 \\
\hline 2000 & 876 & 4,635 & 5,171 & 856 & 531 & 274 & 93,907 & 1,456 \\
\hline 2010 & 972 & 4,842 & 5,344 & 909 & 577 & 304 & 104,137 & 1,701 \\
\hline 2018 & 1,279 & 5,671 & 5,527 & 747 & 686 & 441 & 132,227 & 1,608 \\
\hline 2019 & 1,282 & 5,743 & 5,472 & 752 & 670 & 412 & 133,707 & - \\
\hline
\end{tabular}




\section{Regulation of the Sector}

The healthcare system is mainly governed by the provincial authorities. However, the federal government caters to the need for health laws and policy-making at the national level apart from generating funds from foreign agencies like WHO, Asian Development Bank etc. and other nations, organizing public health facilities and creating awareness through educational programs.

The Pakistan Medical Commission (PMC), the regulatory authority for the monitoring and evaluation of medical colleges, established in 1962 and the College of Physicians and Surgeons Pakistan (CPSP), a formal postgraduate training institute, was established in 1962 as well. Lately PMDC has been replaced by Pakistan Medical Commission by an Act of Parliament in 2020, to accredit, regulate and ensure the quality of medical education. PMC is an authority that shares this role with the Higher Education Commission, Pakistan for regulation of Post-Graduate Medical Education and recognition of medical and dental education. These regulations have been imposed as legal and mandatory requirements by the government. These regulations are intended to maintain strict standards in terms of guidelines, characteristics and criteria to achieve desired quality levels.

Recent regulations focus on the infrastructure evaluation and 'head count' in medical colleges rather than measuring and ensuring educational processes and outcomes. The lack of ambition in accreditation standards is facilitating a rapid growth in the number of medical colleges but the quality of medical education and the outcomes are affected adversely. Sethi and Javaid (2017) stated that the required reforms included reforms to the curriculum to base medical education practice on something other than theoretical training.

\section{The Public-Private Divide}

There were only two medical colleges at the time of independence. It was dominated by the public sector till 1990. The corporate sector was then allowed to establish private medical colleges and the balance inclined towards the private sector. There are currently 47 medical and 11 dental colleges in the public sector and 70 medical and 30 dental colleges in the private sector. Figure 1 shows the rapid increase in private medical colleges over the last two decades.

Anjum (2018) claims that privatization has led to unhealthy competition, poor infrastructure and shortage of teaching faculty, all of which engender incompetent graduates with poor practical skills. The other prominent issues include flaws in admission procedures students are admitted to private medical colleges on lower grades - and a lack of transparency in capitation fees across different medical colleges. The system of medical education and healthcare delivery is negatively affected by maldistribution of resources, lack of updated curriculum, flaws in assessment and deficiency of appropriate faculty development programs. Moreover, the direct involvement of private and commercial interests in the higher education has made it a profit industry.

The admission capacity of all these colleges is approximately 20,000 per year for MBBS, (of which about 4000 are trained each year by the government medical colleges) and 5000 per year for BDS.

Efforts have been made by the government to develop medical colleges in different regions and to admit students based on the criteria of a particular province or region. However, these policies have still not been implemented. Table 3 depicts the distribution of medical colleges and undergraduate places in Pakistan.

\section{Gaining Admission to Medical School}

Medicine is the most sought-after profession in Pakistan and admission to the public sector is highly competitive. The admission policy provides equal opportunities to students from all financial and social strata. The selection procedure includes the marks scored at intermediate/' $A$ ' and Matric/'O' levels in addition to an entrance test conducted across Pakistan. Very few or no medical colleges use interviews as a basis for admission. 
Table 3: Registered Medical and Paramedical Personnel (Progressive) and Expenditure on Health \& Distribution of Registered Medical Colleges and Undergraduate Medical Places in Pakistan

\begin{tabular}{|c|c|c|c|c|c|c|c|c|c|c|c|c|c|c|c|c|c|}
\hline \multirow{4}{*}{ Year } & \multicolumn{8}{|c|}{$\begin{array}{c}\text { National Medical and Health } \\
\text { Establishments, Progressive Number }\end{array}$} & \multicolumn{9}{|c|}{$\begin{array}{l}\text { Registered Medical and Paramedical Personnel (Progressive) } \\
\text { and Expenditure on Health }\end{array}$} \\
\hline & \multirow{3}{*}{ 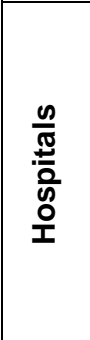 } & \multirow{3}{*}{ 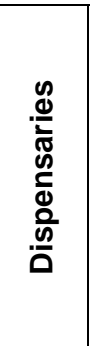 } & \multirow{3}{*}{ 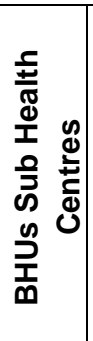 } & \multirow{3}{*}{$\begin{array}{l}\text { 을 } \\
\frac{1}{0} \\
\infty \\
\frac{2}{5} \\
\frac{5}{0} \\
\frac{d}{\pi} \\
\sum\end{array}$} & \multirow{3}{*}{ 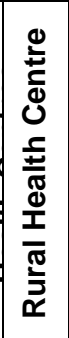 } & \multirow{3}{*}{ 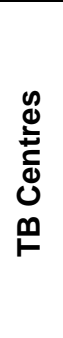 } & \multirow{3}{*}{$\begin{array}{l}\frac{n}{0} \\
\stackrel{0}{0} \\
\frac{\pi}{0} \\
\frac{0}{0}\end{array}$} & \multirow{3}{*}{ 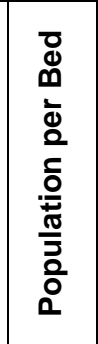 } & \multirow{3}{*}{ 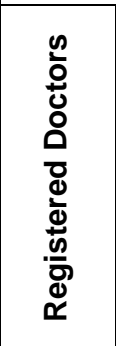 } & \multirow{3}{*}{ 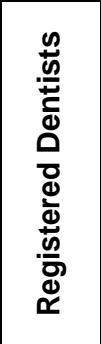 } & \multirow{3}{*}{ 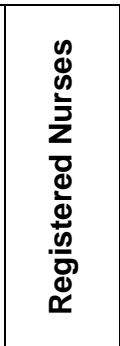 } & \multirow{3}{*}{ 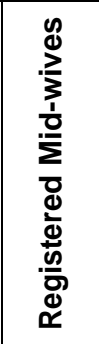 } & \multirow{3}{*}{ 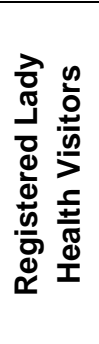 } & \multicolumn{4}{|c|}{ Status } \\
\hline & & & & & & & & & & & & & & \multicolumn{2}{|c|}{ Population } & \multicolumn{2}{|c|}{$\begin{array}{l}\text { Expenditure } \\
\text { (Rs. mn) }\end{array}$} \\
\hline & & & & & & & & & & & & & & 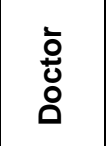 & $\begin{array}{l}\frac{\omega}{.0} \\
\stackrel{\underline{c}}{\Phi} \\
\stackrel{\Delta}{\Delta}\end{array}$ & $\begin{array}{l}\frac{0}{9} \\
\frac{0}{0}\end{array}$ & 등 $\frac{\text { 응 }}{\text { ¿ }}$ \\
\hline 1951 & 306 & 823 & & 110 & - & 3 & 14,741 & 2,454 & & & & & & & & & \\
\hline 1972 & 496 & 2,137 & 249 & 675 & 87 & 82 & 35,337 & 1,792 & 4,802 & 511 & & & & 13,190 & 13,190 & 95.55 & 171.90 \\
\hline 2000 & 876 & 4,635 & 5,171 & 856 & 531 & 274 & 93,907 & 1,456 & 92,838 & 4,165 & 37,528 & 22,525 & 5,443 & 1,529 & 1,529 & 5,944 & 18,337 \\
\hline 2010 & 972 & 4,842 & 5,344 & 909 & 577 & 304 & 104,137 & 1,701 & 144,901 & 10,508 & 73,244 & 27,153 & 11,510 & 1,222 & 1,222 & 28,301 & 66,098 \\
\hline 2019 & 1,279 & 5,671 & 5,527 & 747 & 686 & 441 & 132,227 & 1,608 & 233,261 & 24,930 & $\mid 112,123$ & 41,810 & 20,565 & - & - & 58,624 & 363,154 \\
\hline
\end{tabular}

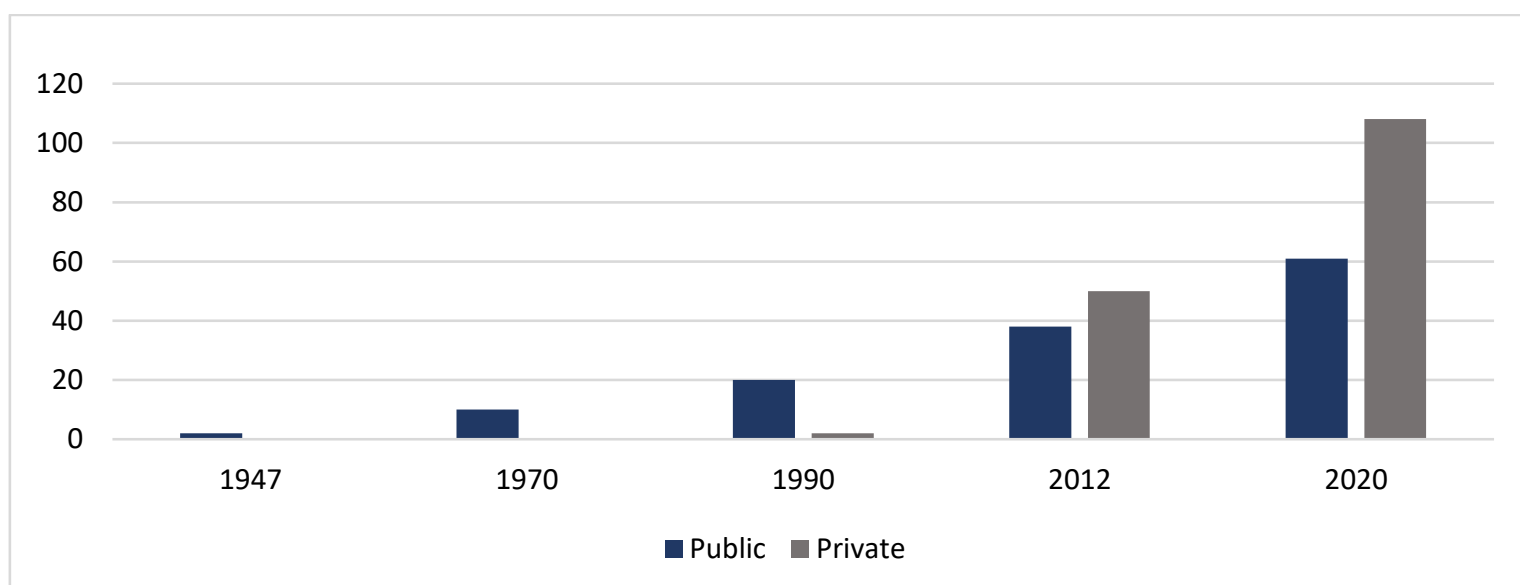

Figure 1: Expansion of Medical Colleges Since 1947

Source: Bokhari (2019) \& Pakistan Medical and Dental Council (2018)

There are challenges to the effectiveness of these entrance tests. Medical educators have already questioned the validity of selecting the candidates on the basis of multiple-choice questions. Entrance exams minimize the significance of clinical skills at both undergraduate \& postgraduate level and simply emphasize knowledge acquisition.

\section{The Medical Curriculum}

Khalid \& Abbassi (2018) claim that medical curricula in Pakistan suffer from traditional didactic teaching methods, absence of integration, limited research activities and little emphasis on the affective domain. Smits, Verbeek \& Buisonjé (2002) suggest that to transform the curricula, it is crucial to bring about vertical and horizontal integration together with an evidence-based approach that emphasizes the clinical and basic sciences equally, using problem-based methodologies to promote deeper learning and critical thinking and a competency-based approach for the acquisition of skills. They noted that a shift towards a community-based curriculum is required for improving community service and care. Although PMDC had placed more 
emphasis on a more integrated teaching framework and skill-based learning, changes have still not come.

The PMDC had recommended that: "a physician shall always maintain the highest standards of professional conduct, being in conformity with principles of honesty, and justice" and encouraged medical colleges to include medical ethics in their taught curriculum. However, only a small percentage of college have adopted medical ethics in their teaching and training.

Assessment strategies are a key aspect of any curriculum. Khan, Biggs, Tabasum \& lqbal (2012) argued that if the assessment system fails to judge the potential and genuine capabilities of a student, then its purpose is lost. Theory examinations in Pakistan mostly follow summative questioning method that is devoid of analytical techniques. Formative assessment and the provision of feedback that gives students the opportunity to learn and assessment of attitude and skills is mostly lacking.

\section{Quality of the Teaching Faculty}

The growth of any educational system relies on the expertise of teaching faculty. According to Anwar and Humayun (2015), as the number of medical colleges has increased in Pakistan, both a shortage of faculty and insufficient faculty development programmes challenge the quality of education. In the academic year 2015-2016, 17 public and private medical colleges were banned by PMDC from admitting students for being deficient in faculty and other facilities. A system for faculty evaluation exists but an absence of incentives makes the faculty anxious and ill-informed about the latest pedagogic methods. Day, Sammons \& Stobart (2007) argue that the quality of medical educators is affected when the eligibility criteria for appointment of faculty are relaxed. A lack of incentives, lack of faculty interest and a shortage of trained faculty as barriers to faculty development.

Beine, Docquier \& Rapoport (2008) pointed towards the loss of public money spent on medical education by the government and manpower due to migration. They recognized the right of an individual to migrate abroad as a justification for the brain-drain. They argued that where government is spending large amounts of public money on the production of healthcare providers and then deprives them disrupts societal justice. Shaikh, Naqvi, Sheikh, Naqvi, \& Bandukda (2012) stated that 35,000 US dollars were being spent on medical education, yet Pakistan was still not able to fight avoidable health problems such as diarrheal diseases, malaria, tuberculosis and high indices of perinatal and maternal mortality. Insecurity, low salaries and poor career structure are the primary factors for this medical brain-drain. To reverse this, urgent interventions were required.

\section{Conclusion}

Quality of healthcare delivery is dependent on improving the standards and quality of education being offered, coordinating the demand and supply of health personnel through effective manpower planning, maintaining data effectively for evidence based policy making and ensuring an equitable distribution of human resource for improving the health of the public at large.

In order to promote social advancement and improve healthcare standards, it is crucial to assess these shortcomings and plan strategies accordingly. There is a dire need for innovative strategies and policies to bring reforms across the entire medical system. In order to improve the productivity of healthcare system, there is an urgent need for taking initiatives that can improve medical education in Pakistan.

\section{Recommendations}

1. Robust national standards that are reliable, valid, measurable, feasible and compatible with the changing local and global scenario should be developed by Regulatory body.

2. An accreditation process should be developed at the level of regulatory body to evaluate the quality \& quantity of existing facilities against set standards. 
3. Geographical \& social inclusivity should be maintained in establishing new institutions $\&$ at the time of enrolment of students.

4. Aptitude test assessing future potential, basic ethical \& moral values supporting a tendency towards competence in healthcare be introduced.

5. A single Aptitude Test should be conducted across Pakistan to ensure merit.

6. Investment on healthcare workers including improved pay packages, quality in work environment and faculty development initiatives should be undertaken.

Declaration of Interest: Authors have no conflict of interest.

\section{References}

Ahmad, I.D, Hanif, S., Asif, M., Malik, M.S.(20192020). Pakistan Economic Survey 2019-2020, pp 197-214

Anjum, M.U., 2018. Level of medical education in Pakistan. Northwest Journal of Medical Sciences, 2(2).

Anwar, M.I. and Humayun, A., 2015. Faculty Development----Looking Through Different
Lenses. Pakistan Armed Forces Medical Journal, 65(1), pp.110-117.

Day, C., Sammons, P. and Stobart, G., 2007. Teachers matter: Connecting work, lives and effectiveness. McGraw-Hill Education (UK).

Habib, M.I. and Khan, K.M., 2017. Overcrowding and possible solutions for a busy paediatric emergency department. J Pak Med Assoc, 67(9), pp.1398-403.

Khalid, F. and Abbasi, A.N., 2018. Challenges faced by Pakistani healthcare system: Clinician's perspective.

Khan, J.J.S., Biggs, J.S., Tabasum, S. and lqbal, M., 2012. Assessment in medical education in Pakistan: evaluation. Biomedica, 28(1), pp.88-94.

Sethi, A. and Javaid, A., 2017. Accreditation System and Standards for Medical Education in Pakistan: It's time we raise the bar. Pakistan journal of medical sciences, 33(6), p.1299.

Sheikh, A., Naqvi, S.H.A., Sheikh, K., Naqvi, S.H.S. and Bandukda, M.Y., 2012. Physician migration at its roots: a study on the factors contributing towards a career choice abroad among students at a medical school in Pakistan. Globalization and health, 8(1), pp.1-11.

Smits, P.B.A., Verbeek, J.H.A.M. and De Buisonje, C.D., 2002. Problem based learning in continuing medical education: a review of controlled evaluation studies. Bmj, 324(7330), pp.153-156. 